\title{
Geochemical modelling for mine site characterization and remediation
}

\author{
D. Kirk Nordstrom ${ }^{1, *}$ \\ ${ }^{1}$ University of Colorado, Boulder, CO 80303, USA
}

\begin{abstract}
Although substantial advances in geochemical modelling have improved our ability to understand and improve mine site characterization and remediation, the limitations of modelling are often underappreciated. Modelers must have expertise in chemistry, geology, hydrology, geochemistry, and microbiology. Those who use codes must understand inorganic chemistry, thermodynamics, and kinetics for water-rock interactions. They must understand that code output is only useful insofar as they understand the limitations of the database and the built-in assumptions. A brief overview of geochemical code development in this paper reveals strengths and weaknesses in modelling capability. Because early predictions of water quality after mine closure often bear little resemblance to actual conditions, this approach should not be relied upon for permitting. Complex large-scale mine sites are not readily amenable to future predictions of hydrogeochemical conditions through modelling, however, modelling can constrain the possible and probable processes that give rise to specific water compositions. Modelling can also help guide remediation planning to find the most cost-effective alternative. Examples are provided for the Questa, New Mexico natural background study, the Summitville Mine, Colorado, and the Pinal Creek Basin, Arizona acidcontaminated aquifer.
\end{abstract}

\section{Introduction}

Last year we published a handbook with the same title as this paper [1]. It is the $4^{\text {th }}$ volume in a series of 6 handbooks on management technologies for metal mining influenced water. In this handbook we emphasize the main hydrogeochemical processes occurring at many mine sites, mass balances, speciation, redox chemistry, efflorescent salts, hydrologic modelling, reactive transport modelling, databases and test cases, case studies, and a summary of what models can and cannot do. This paper summarizes some of the important information from this handbook along with some generalizations about the behaviour of elements in acid mine waters.

\footnotetext{
*Corresponding author: dkn@ usgs.gov
} 


\section{Main Hydrogeochemical Processes}

The main processes occurring at metal mine sites, primarily those mineralized areas formed through hydrothermal alteration, are listed here: (1) sulphide-mineral oxidation, (2) carbonate-mineral dissolution and precipitation, (3) gypsum dissolution/precipitation, (4) oxidation and reduction of several metals and metalloids (Fe, S, Mn, As, Se, Sb, Cr, U, and $\mathrm{V})$, (5) iron precipitation, aluminosilicate dissolution/precipitation, aluminium precipitation, silica precipitation, efflorescent salt formation/dissolution, mixing of waters, evaporation. Most of these reactions are described in stoichiometric detail in [2, 3, 4]. From more than 1300 analyses of mine-influenced waters across the western USA, we have been able to generalize important geochemical properties.

\subsection{Pyrite oxidation and iron precipitation}

A good test for a geochemical code is to have it oxidize pyrite in the presence of just oxygen and water. This is the main process that leads to the formation of acid mine waters.

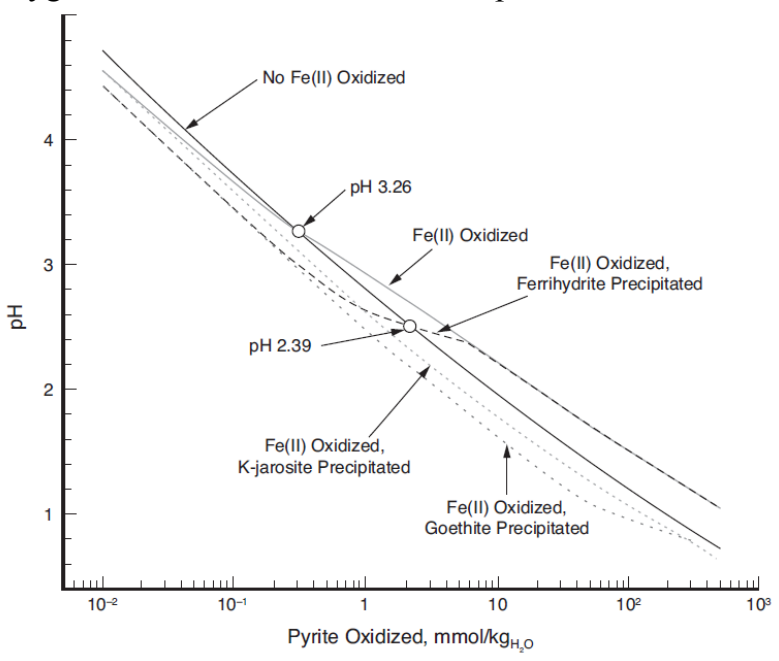

Shown in Fig. 1 is the graphical model of how much the $\mathrm{pH}$ decreases for a given amount of pyrite oxidized, based on calculations made with PHREEQC [4], and reproduced from $[1,5]$. There are several scenarios shown depending on whether the product is an acid ferrous sulfate solution (no $\mathrm{Fe}(\mathrm{II})$ oxidized), a ferric sulfate solution (Fe(II) oxidized), or all of the above with precipitation of ferrihydrite, or jarosite, or goethite. The crossover points are inflections in the curves that identify buffering reactions and

Fig. 1. Change in $\mathrm{pH}$ with the amount of pyrite oxidized [1, 5].

help to explain why most acid mine waters tend to be in the $\mathrm{pH}$ range of $2-3.5$. An important conclusion from this exercise is that the lower $\mathrm{pH}$ crossover point is very sensitive to the $\mathrm{K}_{\mathrm{sp}}$ chosen for the precipitating phase. When the $\log \mathrm{K}_{\mathrm{sp}}=3.0$ (for a

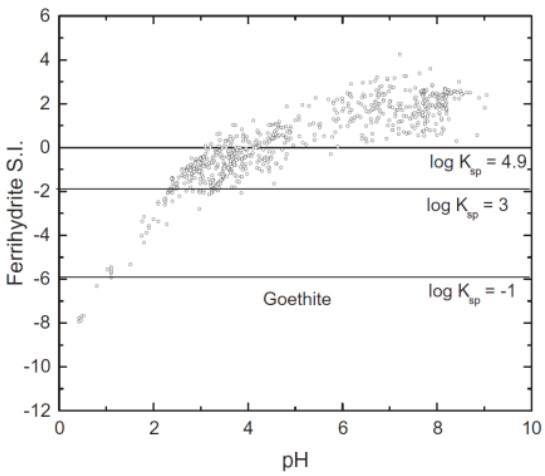

Fig. 2. Ferrihydrite saturation indices for 1300 mine-influenced waters from the western U.S. [6]. fictitious $\mathrm{Fe}(\mathrm{OH})_{3}$ phase), field data matches this trend quite closely and confirms its use [1, $5]$.

Another important observation is the apparent supersaturation for freshly precipitating hydrous ferric oxides (Fig. 2) [6]. This effect is largely caused by nanocolloids passing through the filter membrane and giving $\mathrm{Fe}(\mathrm{III})$ concentrations that are higher than truly dissolved. Measurements of Eh are only sensitive to truly dissolved Fe and allow for the elimination of this artifact. When only those 
samples for which measured = calculated Eh (from Fe(II/III) determinations), the supersaturation effect disappears (Fig. 3). It also shows that for $\mathrm{pH}$ values above 4, iron concentrations are too low to give an equilibrium Nernstian potential for a redox electrode. This should be a warning to anyone attempting to calculate iron speciation from water

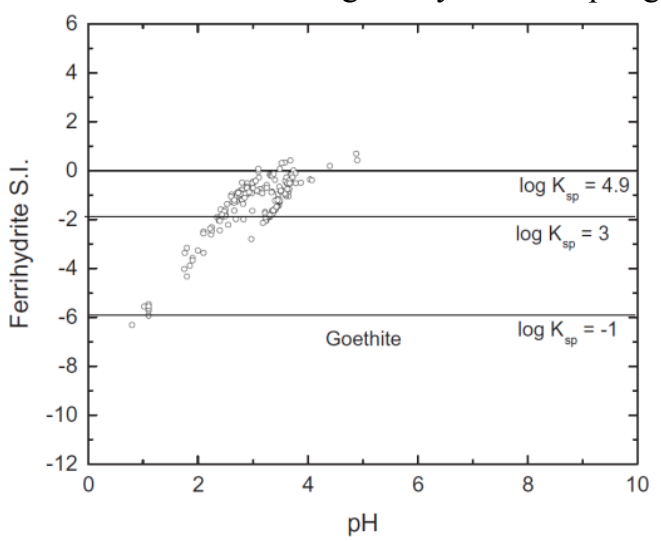

analyses. The very low concentrations of $\mathrm{Fe}(\mathrm{III})$ in natural waters combined with the high degree of organic complexing makes it very challenging. It should be noted that the saturation indices for field samples level off at the most soluble value for freshly precipitating hydrous ferric oxides $\left(\log \mathrm{K}_{\mathrm{sp}}=4.9\right)$ whereas the simulation in Fig. 1 was in agreement with $\log \mathrm{K}_{\mathrm{sp}}=3.0$ because they were samples that had been stored for many weeks to months before remeasuring and the precipitate had aged longer.

Fig. 3. Ferrihydrite saturation indices plotted against $\mathrm{pH}$ after screening out samples where Eh measured did not equal Eh calculated [6].

\subsection{Aluminum precipitation}

Concentrations of $\mathrm{Al}$ are usually the second highest after Fe in acid mine waters. As this water is transported downstream and gradually becomes diluted and neutralized, Al will precipitate at $\mathrm{pH}$ values close to 5 in surface waters and close to 4 in groundwaters. The general behaviour of $\mathrm{Al}$ can also be seen from a plot of $\mathrm{Al}(\mathrm{OH})_{3}$ saturation indices for 1300

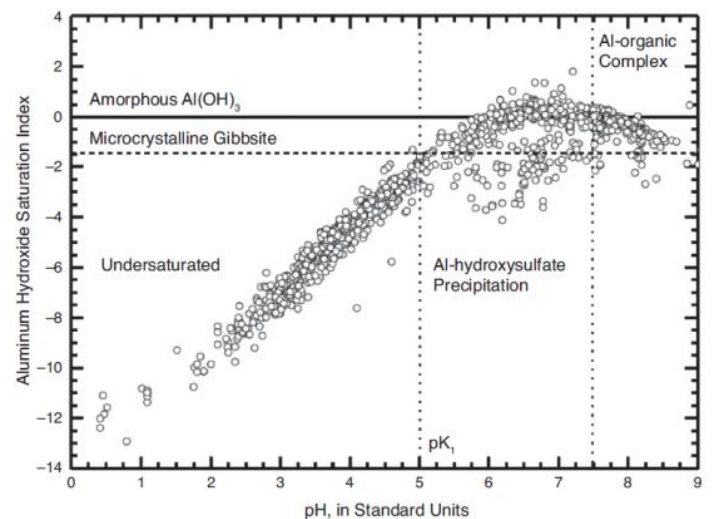
mine-influence waters from the western US (Fig. 4) [1, 5, 6]. A colloidal Al hydroxysulfate phase has been often observed at $\mathrm{pH}$ values close to 5 in many surface waters [1]. This is another good example of a solubility control of an element during the neutralization of an acid mine water. Other mineral solubility controls in these systems include rhodochrosite, calcite, and siderite at circumneutral $\mathrm{pH}$ values, and gypsum over most $\mathrm{pH}$ values.

Fig. 4. $\mathrm{Al}(\mathrm{OH})_{3}$ saturation indices plotted against $\mathrm{pH}$ showing three general areas of dominance: conservative behaviour for surface waters, $\mathrm{pH}<5$, solubility limit, $5<\mathrm{pH}<7$, and Al-organic complexing, $\mathrm{pH}>7[1,5,6]$.

\subsection{Gypsum precipitation}

Most natural waters have $\mathrm{Ca} / \mathrm{Mg}$ ratios $\geq 1$ for both weight and molar ratios. However, in highly acidic mine waters the ratio is commonly reversed. This observation would suggest a mineral solubility control for $\mathrm{Ca}$ (and not $\mathrm{Mg}$ ) and the most likely candidate is gypsum. 
Fig. 5 gives strong evidence for gypsum solubility equilibrium for 1300 mine-influenced water samples. They have been divided up into acid samples $(\mathrm{pH}<4)$ and others $(\mathrm{pH}>4)$. At the higher concentrations, the $\mathrm{Ca} / \mathrm{SO}_{4}$ ratio for gypsum is distinctly forming a boundary for the data points. Saturation indices are also consistent with this interpretation. At lower concentrations the $\mathrm{Ca}$ concentrations are higher than the line because these waters are well below gypsum saturation and have additional $\mathrm{Ca}$ from calcite dissolution.

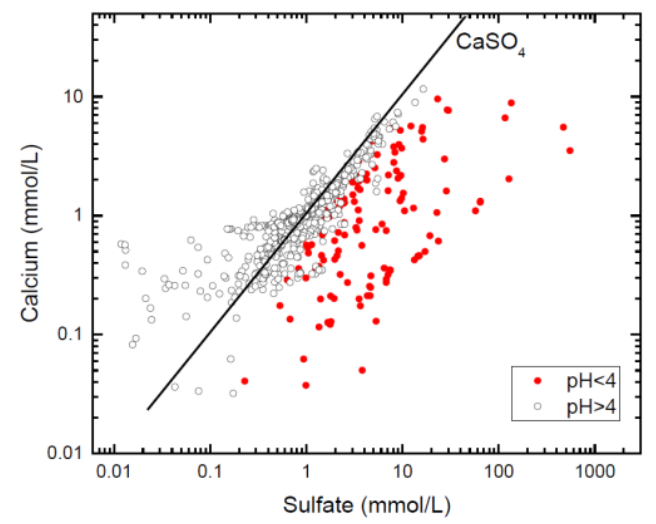

\subsection{Stoichiometric controls}

It is not commonly recognized that acid mine water compositions are also controlled by the stoichiometry of the main reacting mineral, pyrite, after hydrous ferric oxide precipitation has been accounted for. To demonstrate this stoichiometric control, concentrations of $\mathrm{Fe}$ and $\mathrm{SO}_{4}$ are plotted for the same set of 1300 water analyses in Fig. 6. On this plot the stoichiometric ratio for pyrite,

Fig. 5. Calcium concentrations plotted against sulfate concentrations for 1300 mine-influenced water samples from the western US.

$\mathrm{FeS}_{2}$, is also shown as the diagonal solid line. Again, at high concentrations the data

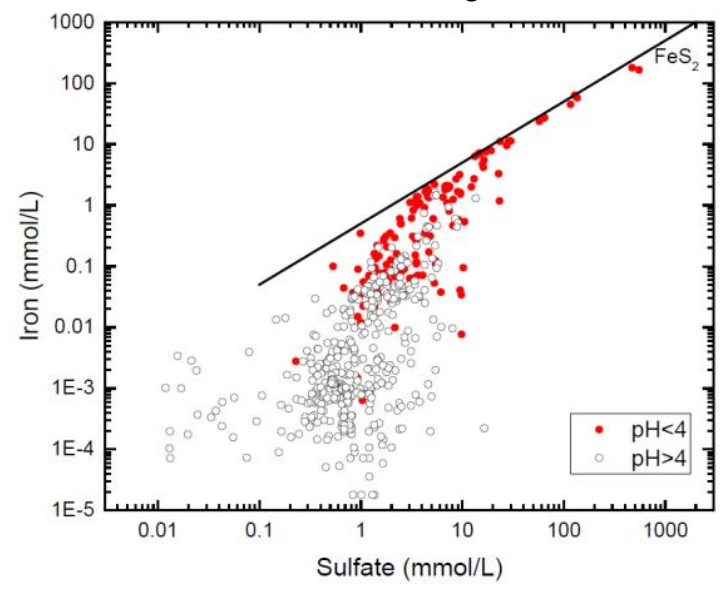
progressively merges toward thestoichiometric line. At lower concentrations, the data points drop well below the line because of substantial precipitation of hydrous ferric oxides and hydroxide sulfates. This stoichiometric control also influences the stoichiometry of soluble salts that can form from the evaporation of acid mine waters [7].

Fig. 6. Iron concentrations plotted against sulfate concentrations for 1300 mine-influenced waters from the western US.

\section{Reactive transport modeling}

Several studies on both reactive transport modelling of acid mine waters in waste piles and in surface waters have helped to characterize and remediate the sources of the mine drainage problem. Some of these are described in [1] and references found therein. For surface drainage from historical mines, the constant-flow tracer injection with synoptic sampling is especially useful in accounting for sources and mass fluxes of mine drainage contaminants. It has also been used to assist in making decisions on the most effective 
combination of treatment alternatives for a complex mine site [1]. This approach is especially useful for characterizing and remediating historical legacy sites [8].

\section{Opportunities for modelling}

Although geochemical modelling has reached a sophisticated level with numerous applications, it also has copious limitations. These are outlined in our handbook [1] along with some basic information on databases, codes commonly used, and the importance of test cases and benchmarks. Unfortunately, geochemical models are often used to make predictions long into the future, more than decades, which cannot be justified. Concurrently, models are not often used for guidance on testing procedures and for planning treatment design, especially on guiding lab scale studies. Reference [9] is an example of such an application for evaluating humidity cell tests. These less-than-desirable situations often arise because (1) industry is under pressure to get the necessary permits, (2) regulators are under pressure and understaffed to deal with modelling reports, (3) both industry and regulators are focused on meeting requirements rather than understanding a specific mine site and how its wastes might or do perform, and (4) the modellers often lack training in one or more of these areas: chemistry, geology, hydrology, or microbiology, nor do they always seek out the appropriate experts in these areas. Many professionals do have this training and they should be more involved in these activities. Geochemical modelling is a challenging task and simply learning how to use a code does not a modeller make.

\section{References}

1. D.K. Nordstrom, A. Nicholson (eds.) Geochemical modelling for mine site characterization and remediation, Soc. Mining Metal. Explor. vol. 4 (2017)

2. G.S. Plumlee, chap. 3, Environmental geochemistry of mineral deposits, Soc. Mining Metal. Explor. Part A, 71 (1999)

3. B. Lottermoser, Mine wastes, $3^{\text {rd }}$ ed., Springer (2010)

4. D.A. Blowes, et al., In B. Sherwood Lollar (ed.) vol. 11, Treatise on geochemistry, 131 (2014)

5. D.L. Parkhurst, C.A.J. Appelo, U.S. Geol. Survey Techn. Methods 6-A43 (2013)

6. D.K. Nordstrom, K.M. Campbell, In J.L. Drever (ed.) vol. 7, Treatise on geochemistry, 27 (2014)

7. D.K. Nordstrom, Appl. Geochem. 26, 1777 (2011)

8. D.K. Nordstrom, In Kittrick, J. A., Fanning, D. S., and Hossner, L. R. (eds.), Acid sulfate weathering, Soil Sci. Soc. Am. Publ. 37 (1982)

9. R.L. Runkel. B.A. Kimball, Environ. Sci. Technol. 36, 1093 (2002)

10. A.S. Maest, D.K. Nordstrom, Appl. Geochem. 81, 109 (2017) 